\title{
Multi-decade biomass dynamics in an old-growth hemlock- northern hardwood forest, Michigan, USA
}

Trends in living aboveground biomass and inputs to the pool of coarse woody debris (CWD)in an undisturbed, old-growth hemlock-northern hardwood forest in northern MI were estimated from multi-decade observations of permanent plots. Growth and demographic data from seven plot censuses over 47 years (1962-2009), combined with one-time measurement of CWD pools, help assess biomass/carbon status of this landscape. Are trends consistent with traditional notions of late-successional forests as equilibrial ecosystems? Specifically, do biomass pools and CWD inputs show consistent long-term trends and relationships, and can living and dead biomass pools and trends be related to forest composition and history? Aboveground living biomass densities, estimated using standard allometric relationships, range from 360-450 Mg/ha among sampled stands and types; these values are among the highest recorded for northeastern North American forests. Biomass densities showed significant decade-scale variation, but no consistent trends over the full study period (one stand, originating following an 1830 fire, showed an aggrading trend during the first 25 years of the study). Even though total above-ground biomass pools have are neither increasing nor decreasing, they have been increasingly dominated, over the full study period, by very large ( $>70 \mathrm{~cm} \mathrm{dbh}$ ) stems and by the most shade-tolerant species (Acer saccharum and Tsuga canadensis).

CWD pools measured in 2007 averaged $151 \mathrm{~m}^{3} /$ ha, with highest values in Acer-dominated stands. Snag densities averaged 27/ha, but varied nearly ten-fold with canopy composition (highest in Tsuga-dominated stands, lowest in Acer-dominated); snags constituted $10-50 \%$ of CWD biomass. Annualized CWD inputs from tree mortality over the full study period averaged 1.9-3.2 Mg/ha/yr, depending on stand and species composition. CWD input rates 
tended to increase over the course of the study. Input rates may be expected to increase over longer-term observations because, a) living biomass is increasingly dominated by very large trees whose dead trunks have longer residence time in the CWD pool, and b) infrequent major disturbances, thought to be important in the dynamics of these forests, have not occurred during the study period but would be expected to produce major, episodic pulses in CWD input.

Few fragments of old-growth cool-temperate forests remain, but such forests can constitute a very large carbon pool on a per-area basis. The carbon sink/source status of these forests remains unclear. While aboveground living biomass at this study site shows no strong aggrading or declining trend over the last half-century, this remains a modest span in the innate time-scale of late-successional forest. The effects of rare disturbances, long-term shifts in composition and size structure, and changes in soil carbon and CWD pools may all influence long-term carbon status. 


\section{Multi-decade biomass dynamics in an old-growth hemlock-northern hardwood forest,}

3 Michigan, $\boldsymbol{U} \boldsymbol{S} \boldsymbol{A}$

4 Kerry D. Woods

5 Natural Sciences

6 Bennington College

7 Bennington VT 05201

8 U.S.A.

\section{Introduction:}

10 Old-growth temperate forests include stands with the highest known densities of living biomass

11 (Keith, Mackey \& Lindenmayer, 2009) and large pools of persistent dead biomass add

12 substantially to total carbon reservoirs. In typical old-growth forests, large individual trees

13 contribute disproportionately to total biomass in the highest-biomass stands (Brown, Schroeder \&

14 Birdsey, 1997; Keith et al., 2009; Keeton et al., 2011). However, these generalizations are based

15 on a relatively few studies with biomass estimates from direct measurement of trees -- fewer than

16 a dozen from northeastern North America (see below) -- and nearly all of these are based on one-

17 time measurements. Consequently, although several recent authors have suggested that old-

18 growth forests can act as carbon sinks as well as important carbon reservoirs (Keeton et al., 2010,

19 2011), the temporal dynamics of living or dead biomass components have been inferred from

20 modeling of forest growth or from space-for-time substitution. Models of old-growth systems

21 often assume, explicitly or implicitly, that community and ecosystem processes are in steady

22 state, but the long-term data-sets necessary to assess such assumptions are rare. A few long-term

23 studies and some simulation models suggest that, in fact, composition may not be steady-state

24 even in old-growth stands (Pacala, Canham \& Ribbens, 1996; Woods, 2004, 2007).

25 Consequently, it is important to assess whether ecosystem properties like biomass density also

26 show significant general or predictable trends in old-growth forests.

27 Using data from permanent plots with multiple remeasurements over 47 years, I calculate

28 aboveground biomass dynamics in old-growth hemlock-northern hardwood forests in northern 
29 Michigan, U.S.. Combined with a one-time measurement of the standing CWD pool, these data

30 allow assessment of behavior of both living and dead biomass and carbon pools in a cool-

31 temperate old-growth forest.

32 Coarse woody debris in (CWD) in hemlock-northern hardwood forests plays an important role in

33 mediating nutrient and carbon cycling (Liu et al., 2006; Gough et al., 2007), in providing

34 substrate for plant germination and seedling growth (Marx \& Walters, 2008; Bolton \& D’Amato,

35 2011), and in structuring habitat for many other species (Harmon et al., 1986; D’Amato, Orwig

36 \& Foster, 2009). Past estimates of CWD density for old-growth hemlock-northern hardwood

37 forests are generally based on one-time inventories, but variation in rates of CWD input could

38 have far-reaching consequences beyond effects on carbon sequestration. In old-growth forests,

39 where large logs can persist on the forest floor for decades, historical variation in biomass and

40 CWD dynamics could leave long-persistent signatures. One-time measurements may, then, be

41 influenced by historical legacies of rare disturbances and not reflect stable conditions. Mesic

42 forests of the upper Great Lakes region appear to be structured predominantly by wind

43 disturbances of varying intensity and frequency (Brewer \& Merritt, 1978; Canham \& Loucks,

44 1984; Woods, 2004). If biomass and CWD inputs are strongly influenced by rare, severe wind

45 events, they may be significantly altered by changing frequency and severity of such events due

46 to predicted climate changes.

47 Specifically, I ask:

48 - Do living biomass pools show consistent trends at decadal time scales?

49 - How do inputs of CWD through tree mortality vary over time at decadal scales?

50 - Are historical CWD input rates, consistent with current CWD constituting a steady-state pool?

51 - Do living and dead biomass pools and trends vary with forest composition and history in

52 consistent ways?

53 Methods:

54 Study-sites and field sampling:

55 Analyses are based on repeated measurements of nineteen 0.2 acre ( $0.081 \mathrm{ha})$ circular permanent 
plots established in 1962 by Eric Bourdo (Ford Forestry Center, Michigan Technological University) within an approximately 5000 ha tract of old-growth forest near Big Bay, MI and within $3 \mathrm{~km}$ of the Lake Superior shoreline (approximately $46^{\circ} 52^{\prime} \mathrm{N} 87^{\circ} 54^{\prime} \mathrm{W}$ ). This tract has been owned by the Huron Mt. Club for over 120 years - since before any logging activity in the immediate vicinity -- and has been free from any active management since acquisition.

61 The Bourdo plots are distributed over a range of habitats and community compositions (Fig. 1).

62 Substrate ranges from acidic, rocky soils developed on thin glacial drift over pre-Cambrian 63 granites to coarse sandy soils, to soils on fine-textured alluvial deposits with relatively high 64 cation availability. Canopy composition ranges from strong hardwood (Acer saccharum Marshall, Tilia americana L.) dominance on high-cation soils to varying mixes of $A$. saccharum and Tsuga canadensis (L.) Carrière on other soils (Woods 2000). Three plots are in a Tsugadominated stand originating following a fire about 1830 (prior to significant European-American presence in the area); all other sampled stands are multi-aged with individual stems exceeding $300 \mathrm{yr}$ old and little evidence of strong cohort structuring (K.D. Woods, unpublished increment core data). All live trees greater than 5 inches in diameter at breast height were measured and marked in 1962 and Bourdo and colleagues remeasured live trees in 1967.

In 1989, I remeasured the Bourdo plots, mapping all stems $>5 \mathrm{~cm}$ dbh for the entire plot and $>2$ $\mathrm{cm}$ for a central sub-plot of $8 \mathrm{~m}$ radius. Painted stem-numbers were still visible, allowing tracking of individual trees from earlier measurements. Subsequently, plots have been remeasured every five years through 2009, documenting growth, mortality, and recruitment. In all measurements, dead trees were recorded as dead standing, tipped up, or broken (with height of break).

In 2007 I censused CWD on the Bourdo plots. For any piece of down wood partially within the plot and $>10 \mathrm{~cm}$ diameter at any point, we measured end diameters and mapped both ends of the piece, recording polar coordinates with a LaserCraft Contour XLRic. Bent or branched CWD segments were subdivided into relatively straight, unbranched segments for mapping. For CWD segments resting on slopes or not resting flat on the ground, we recorded a height (z-coordinate) as well. All CWD segments were, where possible, identified to species and assigned to an

84 identified stem. We measured heights of stumps and diameter at top of stump (approximating top 85 diameter where it was too high to measure directly) and at ground surface (approximating an 
average diameter where ground surface was irregular). If there was significant basal flare, the stump was divided into segments to reduce non-linearity of taper. For snags (standing dead trees with bole intact to diameter $>10 \mathrm{~cm}$ ), we recorded height and diameter at breast height as well as basal diameter.

All CWD segments were scored according to a five-point decay classification similar to that used by other researchers (Angers et al., 2005): Class 1, bark intact and tight; Class 2, significant loss of bark, but wood intact or only slightly decayed; Class 3 , outer layers of wood clearly soft and decaying, but log structurally intact, rigid; Class 4 , decayed and soft throughout, losing structural integrity ('slumping') but still mostly round in cross-section; Class 5, very soft, disintegrating, often moss-covered, no longer round in cross-section (Fig. 2). For the last category, diameters were estimated by averaging approximate vertical and horizontal diameters.

Analyses:

Estimating living biomass and CWD inputs: Above-ground living biomass was estimated for all trees $>12.5 \mathrm{~cm}$ dbh (to conform with the 5 inch minimum dbh recorded in 1962 and 1967), using published dbh-based allometric equations. Equations were selected from (Jenkins et al., 2004) on criteria including: location of development, favoring equations developed for the upper Great Lakes region; size range, favoring relationships based on samples including large trees; and size of sample used to develop relationships (see Supplemental Table 1 for equations used and original sources).

It is not possible to assess either precision or accuracy of resulting estimates, but significant error and bias are probably inescapable. For some species, equations were not available for the upper Great Lakes region. No available allometric equations were fitted using trees larger than about $70 \mathrm{~cm} \mathrm{dbh}$. For all major canopy species in the current data-set, individuals of $>70 \mathrm{~cm}$ dbh are relatively common, with maximum sizes around $100 \mathrm{~cm}$ dbh, and large trees account for substantial fractions of total biomass. Where multiple appropriate equations were available, I compared resulting estimates; estimates for trees up to 50-60 $\mathrm{cm}$ dbh were generally similar among equations but, for larger stems, they diverged substantially - by as much as $30 \%$ for a 90 $\mathrm{cm}$ stem. 
114 Inputs to the CWD pool were estimated using equations for bole biomass only, applied to trees

115 that died during the interval between two measurements. In most cases, CWD input estimates

116 were based on dbh from the last measurement before the tree's death, so any growth after that

117 measurement and before death would be small (annual diameter increments for canopy trees in

118 this study average around 1.0-1.5 mm/yr depending on species and interval, and growth rates are

119 typically reduced in the years immediately preceding death (Woods 2000)). However, for the 22-

120 year interval between 1967 and 1989, I used diameter measurements of standing dead trees taken

121 in 1989 where loss of bark and decay were not significant. As much as $30 \%$ of above-ground

122 living biomass, in large trees, can be in branches, twigs, and foliage. However, only the very

123 largest branches would contribute significantly to CWD as measured here, and allometric

124 equations typically do not allow differentiation of branches by size. The effects of using dbh for

125 up to several years prior to death and of using bole biomass only will result in some systematic

126 underestimation of CWD input rates. CWD inputs are presented as annualized rates, evenly

127 distributed within each interval between measurements.

128 Estimating CWD volume and mass: Volume of individual CWD segments was estimated by 129 treating them as regular conic frusta; the height (length) of the frustum was derived from the 130 mapped polar coordinates of the end-points (using three-dimensional coordinates where 131 appropriate). For CWD segments lying only partially within the plot, I calculated the length

132 within the plot perimeter and estimated diameter at that point assuming linear taper between

133 measured ends; volume was calculated for the portion within the plot only. Stumps were also

134 treated as frusta (or multiple frusta where flare led to sectioned measurements). Snag volume

135 was estimated using similar approaches unless appropriate dbh-based allometric equations for

136 bole volume were available (Supplemental Table 1). CWD volume was converted to dry biomass

137 using taxon-specific relationships between density and decay class from Liu et al. (2006), which

138 uses decay classes nearly identical to those used here (for unidentifiable fragments in decay

139 classes 3 to 5, values for 'all species' were used).

140 Plot groupings: For comparisons across stands of different history and composition, I used plot 141 groupings based on location, habitat, and canopy composition dominance (see Woods 2000). The

142 Acer group includes plots in two localities with fine-textured, high-cation soils and near-complete 143 hardwood dominance and with maximum ages $>300$ years. The Tsuga group includes two plots 144 in a single stand with high hemlock dominance and apparent maximum age of about 300 years 
145 (unpublished increment core data). Six plots on level, coarse, deep sandy soils, with upper

146 canopy dominated by hardwoods but significant subcanopy and codominant Tsuga component

147 were initially assigned to a 'mixed flat' group and three plots in areas of shallower soils on

148 moderate slopes and with mixed hardwood-Tsuga canopy were treated as a 'mixed slope'.

149 However, all results and trends were very similar for these two groups, and they are pooled here

150 as a single 'mixed' plot group. Finally, three plots in the 1830 burn area (slight to moderate

151 slopes, and strong Tsuga dominance) were assigned to the 'burn' group.

152 Statistical approaches: Changes in plot-level characteristics over the full study period were 153 assessed using paired t-tests comparing starting and ending values with appropriate

154 transformations. Differences among compositional plot groupings were assessed using non155 parametric Kruskal-Wallis tests with post hoc Mann-Whitney pair-wise tests with Bonferroni 156 corrections.

\section{Results:}

158 Aboveground living biomass: Aboveground living biomass densities at the most recent

159 measurement date ranged from about 360 to $450 \mathrm{Mg} /$ ha within plot groups (Supplemental Table 2

160 for values by species and plot). Trends over 47 years were not consistent over time or among

161 groups (Table 1, Fig. 3). In the Acer and mixed groups total change was less than 10\% of initial

162 values, although the mixed group reached a peak biomass density in 1994 nearly 20\% greater

163 than the initial value. Both Tsuga-dominated groups ('Tsuga' and 'burn'), however, showed more

164 consistent and substantial overall increases in biomass, although biomass density in the 'burn'

165 group decreased by about 10\% (after a ca. 25\% increase) in the last decade of the study.

166 Averaged over all plots, biomass density increased from $358 \mathrm{Mg} / \mathrm{ha}$ in 1962 to $378 \mathrm{Mg} / \mathrm{ha}$ in

1672009 , but this change was not statistsically significant (paired t-test, $\mathrm{p}>0.05$ ).

168 The proportion of total biomass in stems $>70 \mathrm{~cm} \mathrm{dbh}$, over all plots, increased from $6 \%$ in 1962 169 to $14 \%$ in 2009 (paired t-test, arcsin conversion, p<0.01) (Fig. 4a). Acer plots were most strongly

170 dominated by very large trees over the entire study period (Fig. 5), but proportional

171 representation peaked in 1989. Tsuga and mixed plots saw more continuous increases in big-tree

172 fractions, while large stems never exceeded 5\% of biomass in the 'burn' plots (all individuals $>70$

173 cm dbh were Populus grandidentata Michx., and all died by 2004). 
174 In all plot groups where Tsuga had significant presence, it increased as a proportion of total 175 biomass (Fig. 6, Supplemental Table 2). Acer biomass changes varied in absolute values, but its 176 proportional importance decreased except in the 'Acer' plot group. Betula alleghaniensis Britton 177 and Tilia americana biomass showed varying trends, but increases were generally modest while

178 declines were substantial in some plot groups. Eleven other species (Woods 2000, Supplemental

179 Table 2) reached diameters of $12.5 \mathrm{~cm}$, but, in total, represented no more than $8 \%$ of total

180 biomass except in the 'burn' group, where they were 17\% of total biomass in 1962 (Populus

181 grandidentata constituted more than half of this portion). In all plot groups, representation of

182 minor species decreased consistently and substantially over the course of the study as large stems

183 died without replacement.

184 Coarse Woody Debris: Coarse woody debris pools in 2007, including snags, averaged $151 \mathrm{~m}^{3} / \mathrm{ha}$ 185 (range among plot groups, 119-178 $\mathrm{m}^{3} / \mathrm{ha}$ ) and $46.0 \mathrm{Mg} / \mathrm{ha} \mathrm{(38-52} \mathrm{Mg/ha)} \mathrm{(Table} \mathrm{2,} \mathrm{Fig.} \mathrm{7,}$ 186 Supplemental Table 3). CWD densities were significantly higher in Acer-dominated stands, but 187 were not otherwise different among plot groups ( $\mathrm{p}>0.05$, Kruskal-Wallis test, post hoc Mann188 Whitney pair-wise tests with Bonferroni correction). The proportion of CWD in the first two 189 decay classes was substantially lower in the Acer group (31\% by mass) compared to other groups 190 (47-61\%), and highest for the 'burn' group. Snag densities ranged from 9.9/ha ('Acer' group) to 191 98.8/ha ('burn') with an overall average of 27.3/ha. Snags constituted 10-20\% of total CWD 192 biomass for mixed and hardwood dominated plot groups, but $49 \%$ for the 'Tsuga' group and 99\% 193 for the burn group (Supplemental Table 3).

194 Annualized inputs to the CWD pool (total stem mass of dying trees divided by length of 195 measurement interval) averaged 1.9-3.2 Mg/ha/yr, depending on plot group, for the entire 47 year 196 period (Fig. 8). Fluctuations among measurement intervals can be attributed to the effects of 197 occasional large-tree mortality in relatively small sample areas. However, both mixed andTsuga-

198 dominated fire group showed large increases in CWD input in the second half of the study period, 199 from 1989-2009, compared to 1962-1989 (Figure 7, Table 3). Rates of CWD input nearly 200 quadrupled over the last two decades, compared to earlier decades, for the 'burn' plot group.

201 Average annual CWD input was 13\% (by mass) of total CWD in decay classes 1 and 2 in 2007. 202 For plot groups, corresponding values ranged from 6\% ('burn' group) to $20 \%$ ('Acer' group). 
203 These proportions are likely somewhat underestimated because input estimates do not incorporate

204 large branches that were included in the CWD pool as measured in 2007.

\section{Discussion:}

206 Aboveground biomass: Total aboveground woody biomass estimates for the Huron Mt. stands are 207 among the highest obtained for eastern North American forests. Other estimates for old-growth

208 hemlock-northern hardwood forests in the upper Great Lakes range from 200 to $325 \mathrm{Mg} / \mathrm{ha}$

209 (Mroz et al., 1985; Morrison, 1990; Rutkowski \& Stottlemyer, 1993); all plot groups in this study 210 exceed this range, with maximum values, in the Acer and Tsuga groups, at $430 \mathrm{Mg} / \mathrm{ha}$, exceeding 211 the highest previous estimates by a third. These values are comparable to estimates for southern

212 Appalachian cover forests (Busing, 1993) although temperate coniferous forests in the Pacific 213 northwest attain significantly higher biomass densities (e.g., up to $500 \mathrm{Mg} / \mathrm{ha}$ in Janisch 2001).

214 These high values could be, in part, an artifact of original plot selection in 1962, which might

215 have favored stands with more undisturbed appearance, while cited studies might be based on

216 less biased site selection or on larger areas of stands encompassing a range of disturbance.

217 However, Lake Superior coastal climates are distinctive, and mesic forests near the lakeshore

218 appear to experience unusually low frequencies of severe disturbance (Frelich \& Lorimer, 1991), 219 permitting high living biomass accumulation.

220 There were no clear, overall trends in biomass density over the full 47 years of the record; rather, 221 biomass dynamics were dominated by shorter-term fluctuations (Fig. 3). For example, Acer and, 222 to a lesser extent, Tsuga groups showed sharp decreases in biomass between 1962 and 1967, 223 while all groups increased in biomass density during the long measurement interval from 1967 224 and 1989. Biomass increases in the first half of the study were proportionally greatest in the 225 'burn' group, and there was virtually no mortality in this group (Woods 2000), suggesting that, 226150 years after stand initiation, the stand remained in an aggrading phase. All groups show both 227 increases and decreases in the four 5-year intervals since 1989, and trends are not synchronous 228 among groups or stands. This pattern suggests biomass dynamics dominated by generally modest 229 but irregular mortality of large trees superimposed on biomass gains through growth of surviving 230 individuals. After 1990 (about 160 years after stand initiation), the 'burn' stand no longer shows 231 an aggrading trend. 
232 However, even though strong trends were not evident in total living biomass, directional changes

233 are evident in forest structure, with an approximate doubling of proportions of biomass in trees $>$

$23470 \mathrm{~cm} \mathrm{dbh}$ (Figs. 4a, 5). Higher proportions (ca. 30\%) of biomass in stems $>70 \mathrm{~cm}$ dbh were

235 observed by Brown et al. (1997) in old forests of the lower midwest, but the largest stems in

236 many of these stands were Quercus spp, while intermediate size-classes were dominated by Acer

237 saccharum and Fagus grandifolia, suggesting that large Quercus stems were remnants of forest

238 structures established under past, fire-dominated disturbance regimes. Tyrrell and Crow (1994)

239 suggest that, in Tsuga-dominated forests of the upper Great Lakes, significant representation of

240 stems $>70 \mathrm{~cm}$ dbh indicates stand ages $>275-300$ yr. Here, biomass proportions in this size

241 category approached or exceeded $20 \%$ by 2009 for Acer and Tsuga stands. The initial presence

242 (and subsequent mortality without replacement -- unpublished results, K. Woods) of large

243 individual trees of shade-intolerant species (Quercus rubra, Pinus strobus, Populus

244 grandidentata) in the 'mixed slope' group may be the signature of significant disturbance, but

245 cores of late-successional canopy trees $>250$ years old suggest that such disturbances were either 246 partial or ca. 300 years ago.

247 Earlier analysis of compositional trends in non-burned plots over the first 32 years of the study 248 suggested gradual competitive displacement of mid-tolerant species (Betula alleghaniensis, Tilia 249 americana) with increasing dominance of Acer saccharum or Tsuga canadensis, depending on 250 soil properties (Woods, 2000). Biomass trends described here are consistent with this picture for 251 the full 47 years of the data-set. In all plot groups, proportional representation of Acer and Tsuga 252 has increased at the expense of all other species (Fig. 6). This is particularly evident in the 'burn' 253 group, where proportional representation of Tsuga in the living biomass pool has increased 254 continuously, particularly in the last two decades when total biomass has not been increasing 255 consistently.

256 Taken together, these trends are consistent with the interpretation that old-growth hemlock257 northern hardwood stands are typically in varying stages of long-term response to intermediate 258 (or, in the case of the 'burn' plot-group and some individual plots, severe) disturbance (Abrams \& 259 Orwig, 1996; Woods, 2004, 2007; Bouchard, Kneeshaw \& Bergeron, 2006; Stueve et al., 2011). 260 Most notably, in terms of biomass dynamics, an approximate equilibrium in total biomass density 261 is maintained while both size distributions and species representation show directional shifts. 
262 Coarse woody debris: Overall, $2007 \mathrm{CWD}$ volume (averaging $151 \mathrm{~m}^{3} / \mathrm{ha}$ for all plots) and

263 biomass (46 Mg/ha), with about $25 \%$ of these values in standing snags, are within the range of

264 earlier findings for old-growth forests of the upper Great Lakes and northeastern forest regions

265 (Hura \& Crow; Tyrrell \& Crow, 1994; Goodburn \& Lorimer, 1998; McGee, Leopold \& Nyland,

266 1999; Angers et al., 2005; D’Amato, Orwig \& Foster, 2008). Conifer CWD generally shows

267 lower decay rates than hardwood CWD of comparable size (Harmon et al., 1986). However,

268 studies comparing total CWD pools between hardwood and conifer-dominated forests have

269 shown inconsistent results. Most of these, however, have focused on successional or boreal

270 forests (Lee et al., 1997; Pedlar et al., 2002). Here, the 'Tsuga' plot group had relatively low

271 CWD densities compared to other groups in this study, while the strongly hardwood-dominated

272 'Acer' group had very high values, suggesting substantially higher recent input rates for hardwood

273 stands. Tyrrell and Crow (1994) show CWD increasing with age in Tsuga stands; values here are

274 in the highest range for their study (suggesting stand ages $>300 \mathrm{yr}$ ). CWD densities for the Acer

275 group are among the highest published for cool-temperate deciduous forests. These pools are

276 dominated by wood in the most decayed classes, possibly suggesting results of a significant,

277 landscape-scale disturbance several decades ago; this may be consistent with the sharp decrease

278 in biomass observed for these plots between 1962 and 1967.

279 Inputs of CWD from 1962-2009 averaged $2.5 \mathrm{Mg} / \mathrm{ha} / \mathrm{yr}$ over all plots -- equivalent to $5.5 \%$ of the

2802007 total CWD pool and $11.7 \%$ of the pool of decay classes 1 and 2 . If CWD pools are

281 relatively stable or equilibrial, this implies an average residence time of around two decades

282 overall and one decade in the relatively intact classes 1 and 2. Few studies have attempted to

283 estimate residence time for CWD in hemlock-northern hardwood forests, and none have used

284 long-term monitoring of mortality to assess input rates, so it is difficult to draw comparisons.

285 However, existing estimates of residence time vary substantially. Zielonka (2006) estimates

286 residence times of 13 and 24 yrs in classes 1 and 2 in conifer-dominated forests in Poland --

287 substantially longer than turnover times suggested here under steady-state assumptions.

288 However, estimates from old-growth hardwood forest in Ontario suggest a half-life for 'down

289 woody debris' (exclusive of snags) of ca. $20 \mathrm{yr}$, with mean age of wood in classes 1 and 2 of three

290 and five years (Vanderwel et al., 2008), and CWD in a logged, successional forest in New

291 Hampshire decreased in mass by 90\% in 20 years (Arthur, Tritton \& Fahey, 1993). Given

292 variations in approach (inclusion of snag mass or not, differences in decay class definitions) and

293 coarseness of estimates, these decay rates could be compatible with current CWD pools being in 
295 Nearly all previous studies of CWD dynamics are based on one-time measurements and space296 for-time substitutions; consequently conclusions about trends over time are strongly assumption-

297 laden. Direct measurement of trends in CWD input, based on long-term permanent-plots with

298 multiple remeasurements, permits an unusual direct assessment of trends. Most strikingly, 299 overall per-year CWD input increased by nearly half between the first 27 years of the study and 300 the last 20 years (from 2.1 to $3.1 \mathrm{Mg} / \mathrm{ha} / \mathrm{yr}$ ), suggesting non-equilibrial status of biomass and 301 carbon dynamics at decadal scales. Such trends might be anticipated in cohort-structured stands 302 where one or more cohorts are reaching senescence; consistent with this interpretation, overall 303 canopy-tree mortality rate increased from $0.6 \% / \mathrm{yr}$ for $1962-1989$ to $0.9 \% / \mathrm{yr}$ from $1989-2009$.

304 These increases were most evident in the youngest stands -- the 'burn' group -- with an increase 305 in CWD input from 0.8 to $3.0 \mathrm{Mg} / \mathrm{ha} / \mathrm{yr}$ for these two periods, and in the mixed plots (increase 3062.1 to $3.9 \mathrm{Mg} / \mathrm{ha} / \mathrm{yr})$.

307 Over all plots, size distribution of stems contributing to total mortality and CWD input did not 308 show the increasing dominance of large stems seen in the living biomass pool (Fig. 4b), but size distributions of CWD input do suggest an increased importance of smaller to mid-size canopy trees (ca. $25-50 \mathrm{~cm} \mathrm{dbh}$ ) in the last two decades. This may be due to enhanced mortality of 311 suppressed sub-canopy trees and sub-dominant canopy trees.

312 The 'Acer' group, with the highest CWD inputs in 1962-1989, and the 'Tsuga' group showed less 313 change; if these two groups are in approximate steady-state, implied residence time of CWD is 314 about 16 years overall and 5 years in decay classes 1 and 2 for the hardwood-dominated 'Acer'

315 plots, and about 22 years and 10 years for the 'Tsuga' group. This is in keeping with general 316 expectations of more rapid decay of hardwood CWD and, for Acer plots, consistent with 317 estimates from Liu et al. (2006) and Gauch et al. (2007), who estimate a decomposition rate318 constant of 0.09/yr, implying residence time of 11-13 yrs (Liu et al. 2006), for forests of similar 319 composition. Arthur et al. (1993) estimate 90\% loss of CWD biomass in $23 \mathrm{yr}$ for hardwoods in

320 New Hampshire; this would be a more advanced state of decay than in the classes incorporated in 321 this study. However, calculations based on steady-state assumptions should be approached 322 cautiously; 47 years is much less than half of canopy turnover time estimates for similar forests 323 (Frelich \& Graumlich, 1994; Dahir \& Lorimer, 1996). 
324 However, several factors make these interpretations very tentative. First, input estimates here 325 may be low because of exclusion of branch biomass for dying trees. Second, changes in size 326 distribution towards increasing dominance of very large stems suggest that CWD inputs will tend

327 to shift to larger-diameter materials, with correspondingly longer residence-times. Finally, over

328 longer periods, canopy-tree mortality may be dominated by pulses associated with more severe 329 disturbance (Woods 2004, 2007, Frelich \& Lorimer 1991). No such events have occurred during

330 the study period or, as suggested by size and age structures (Woods 2000), in several decades 331 prior to its initiation. Thus long-term average inputs are likely to be greater than those observed 332 here. All of these factors suggest that estimates of recent CWD input for the study plots may be 333 an underestimate of longer-term, future inputs. If so, CWD pools may be expected to increase.

334 Sources of error and uncertainty: While the long-term data-set suppporting these analyses 335 supports unusually detailed insight into carbon/biomass dynamics and relationships between tree 336 growth and mortality and CWD pools in old-growth forests, some important uncertainties and 337 potential errors remain. Two of these are likely most important.

338 First there are large uncertainties connected with biomass estimation for very large trees $(>70 \mathrm{~cm}$ $339 \mathrm{dbh}$ ) that constitute an increasing proportion (up to 30\%) of total above-ground living biomass.

340 Until allometric relationships for large stems become available, it will be difficult to reduce this 341 uncertainty. All estimates of biomass in late-successional forests are subject to the same potential 342 errors.

343 Second, even though the study period of 47 years is unusually long, canopy-tree mortality rates of $344<1 \% / y r$ indicate that it remains brief in the innate time-scale for dynamics in these forests.

345 Observed dynamics represent less than half of a single generation of canopy trees. Further, 346 multiple studies have suggested that dynamics in similar forests are strongly influenced by major 347 disturbance episodes with return times measured in centuries (Woods 2004, 2007, Frelich 1991).

348 Such events would have major consequences for CWD dynamics, but none have occurred at this 349 site during the study period.

350 Conclusions 
351 These results provide at least partial answers to my four initial questions; all can be more

352 confidently addressed only with longer-term observation:

353 Do living biomass pools show consistent trends at decadal time scales in these old-growth, late-

354 successional forests? Overall, biomass densities observed here are exceptionally high in the

355 context of published estimates for northeastern North America. However biomass estimates from

356 seven measurements over nearly five decades indicate no consistent long-term trend. Live

357 biomass pools are neither aggrading or declining overall, but most stands show significant

358 fluctuations at a decadal scale. Three plots in an even-aged, post-fire stand appeared to be

359 aggrading for the first 25 years of the study, but this trend ended about 1990 (stand age ca. 160

360 yr). These results do not suggest that above-ground living biomass pools are significant carbon

361 sinks, but longer-term studies will be required to make this conclusion with high confidence.

362 Consistent long-term increases in the contribution of very large trees to living biomass indicate

363 non-equilibrial demography and the potential for sharp biomass fluctuations in future decades

364 with mortality of these trees.

365 What are patterns of CWD input through tree mortality at decadal scales? Fluctuation in CWD

366 input rates are large, and individual plots are strongly influenced by occasional mortality of large

367 canopy trees. However, in nearly all plot groups, input rates increased significantly from the first

36827 years of the study to the last 20 years. This pattern is consistent with the suggestion from

369 previous analyses (Woods 2000) that stand dynamics are influenced by episodic events translated

370 through tree demography; in terms of size-structure and species composition these stands may be

371 cohort-structured and non-equilibrial.

372 Are historical CWD input rates and current CWD pools consistent with a steady-state

373 assumption regarding CWD reserves? Estimates of CWD input and standing volume here do not

374 allow confident projections regarding wheter CWD pools are stable, increasing, or decreasing.

375 However, increasing dominance of large canopy trees (with the longer residence time of larger

376 tree boles in the CWD pool) and the absence of major disturances during the study period to date

377 may be consistent with an expectation of long-term increases in carbon pools in dead biomass

378 with future mortality of these large trees, even if living biomass is not increasing.

379 How are forest composition and history related to biomass and carbon dynamics? While total 
380 CWD density did not show marked variation among stand types, Tsuga-dominated stands

381 exhibited consistently lower input rates. High fluctuation in CWD input rates may be consistent

382 with cohort-structured mortality related to effects of rare disturbances on tree establishment rates

383 (Woods 2000, 2004, 2007), particularly in hardwood-dominated stands.

384 Acknowledgements:

385 Study plots were established by Eric Bourdo of the Ford Forestry Center, Michigan

386 Technological University; information about plot location and data from 1962 and 1967

387 measurements were generously shared by Dr. Bourdo and the staff at the Ford Forestry Center.

388 Approximately 25 Bennington College undergraduate students have participated in field

389 measurements since 1989. The Huron Mt. Wildlife Foundation has provided logistical support

390 through the facilities of the Ives Lake Research Station.

\section{References cited:}

Abrams MD, Orwig DA. 1996. A 300-year history of disturbance and canopy recruitment for cooccurring white pine and hemlock on the Allegheny Plateau, USA. Journal of Ecology $84: 353-363$.

Angers VA, Messier C, Beaudet M, Leduc A. 2005. Comparing composition and structure in oldgrowth and harvested (selection and diameter-limit cuts) northern hardwood stands in Quebec. Forest Ecology and Management 217:275-293.

Arthur MA, Tritton LM, Fahey TJ. 1993. Dead bole mass and nutrients remaining 23 years after clear-felling of a northern hardwood forest. Canadian Journal of Forest Research 23:1298-1305.

Bolton NW, D’Amato AW. 2011. Regeneration responses to gap size and coarse woody debris within natural disturbance-based silvicultural systems in northeastern Minnesota, USA. Forest Ecology and Management 262:1215-1222.

Bouchard M, Kneeshaw D, Bergeron Y. 2006. Tree recruitment pulses and long-term species coexistence in mixed forests of western Québec. Ecoscience 13:82-88.

Brewer R, Merritt PG. 1978. Wind throw and tree replacement in a climax beech-maple forest. Oikos 30:149-152.

Brown S, Schroeder P, Birdsey R. 1997. Aboveground biomass distribution of US eastern 
hardwood forests and the use of large trees as an indicator of forest development. Forest Ecology and Management 96:37-47.

Busing RT. 1993. Three decades of change at Albright Grove, Tennessee. Castanea 58:231-242. Canham CD, Loucks OL. 1984. Catastrophic windthrow in the presettlement forests of Wisconsin. Ecology 65:803-809.

D’Amato AW, Orwig DA, Foster DR. 2008. The influence of successional processes and disturbance on the structure of Tsuga canadensis forests. Ecological Applications 18:1182-1199.

D’Amato AW, Orwig DA, Foster DR. 2009. Understory vegetation in old-growth and secondgrowth Tsuga canadensis forests in western Massachusetts. Forest Ecology and Management 257:1043-1052.

Dahir SE, Lorimer CG. 1996. Variation in canopy gap formation among developmental stages of northern hardwood stands. Canadian Journal of Forest Research 26:1875-1892.

Frelich LE, Graumlich L. 1994. Age-class distribution and spatial patterns in an old-growth hemlock-hardwood forest. Canadian Journal of Forest Research 24:1939-1947.

Frelich LE, Lorimer CG. 1991. Natural disturbance regimes in hemlock-hardwood forests of the upper Great Lakes region. Ecological Monographs 61:145-164.

Goodburn JM, Lorimer CG. 1998. Cavity trees and coarse woody debris in old-growth and managed northern hardwood forests in Wisconsin and Michigan. Can. J. For. Res 28:427438.

Gough CM, Vogel CS, Kazanski C, Nagel L, Flower CE, Curtis PS. 2007. Coarse woody debris and the carbon balance of a north temperate forest. Forest Ecology and Management 244:60-67.

Harmon ME, Franklin JF, Swanson FJ, Sollins P, Gregory SV, Lattin JD, Anderson NH, Cline SP, Aumen NG, Sedell JR. 1986. Ecology of coarse woody debris in temperate ecosystems. Advances in ecological research 15:302.

Hura CE, Crow TR. Woody debris as a component of ecological diversity in thinned and unthinned northern hardwood forests. Natural Areas Journal 24:57-64.

Janisch JE. 2001. Carbon storage in a Pacific Northwest conifer forest ecosystem: a chronosequence approach.

Jenkins JC, Station NR, States U, Service F. 2004. Comprehensive Database of Diameter-based Biomass Regressions for North American Tree Species. US Dept. of Agriculture, Forest Service, Northeastern Research Station. 
Keeton WS, Chernyavskyy M, Gratzer G, Main-Knorn M, Shpylchak M, Bihun Y. 2010.

Structural characteristics and aboveground biomass of old-growth spruce-fir stands in the eastern Carpathian mountains, Ukraine. Plant Biosystems 144:148.

Keeton WS, Whitman AA, McGee GC, Goodale CL. 2011. Late-successional biomass development in northern hardwood-conifer forests of the northeastern United States. Forest Science 57:489-505.

Keith H, Mackey BG, Lindenmayer DB. 2009. Re-evaluation of forest biomass carbon stocks and lessons from the world's most carbon-dense forests. Proceedings of the National Academy of Sciences 106:11635.

Lee PC, Crites S, Nietfeld M, Nguyen HV, Stelfox JB. 1997. Characteristics and origins of deadwood material in aspen-dominated boreal forests. Ecological Applications 7:691701.

Liu WH, Bryant DM, Hutyra LR, Saleska SR, Hammond-Pyle E, Curran D, Wofsy SC. 2006. Woody debris contribution to the carbon budget of selectively logged and maturing midlatitude forests. Oecologia 148:108-117.

Marx L, Walters MB. 2008. Survival of tree seedlings on different species of decaying wood maintains tree distribution in Michigan hemlock-hardwood forests. Journal of Ecology.

McGee GG, Leopold DJ, Nyland RD. 1999. Structural characteristics of old-growth, maturing, and partially cut northern hardwood forests. Ecological Applications 9:1316-1329.

Morrison IK. 1990. Organic matter and mineral distribution in an old-growth Acer saccharum forest near the northern limit of its range. Canadian Journal of Forest Research 20:13321342.

Mroz GD, Gale MR, Jurgensen MF, Frederick DJ, Clark III A. 1985. Composition, structure, and above ground biomass of two old-growth northern hardwood stands in Upper Michigan. Canadian Journal of Forest Research 15:78-82.

Pacala SW, Canham CD, Ribbens E. 1996. Forest models defined by field measurements: Estimation, error analysis and dynamics. Ecological Monographs 66:1-43.

Pedlar JH, Pearce JL, Venier LA, McKenney DW. 2002. Coarse woody debris in relation to disturbance and forest type in boreal Canada. Forest Ecology and Management 158:189_ 194.

Rutkowski DR, Stottlemyer R. 1993. Composition, biomass and nutrient distribution in mature northern hardwood and boreal forest stands, Michigan. American Midland Naturalist 130:13-30. 
Stueve KM, Perry CH (Hobie), Nelson MD, Healey SP, Hill AD, Moisen GG, Cohen WB, Gormanson DD, Huang C. 2011. Ecological importance of intermediate windstorms rivals large, infrequent disturbances in the northern Great Lakes. Ecosphere 2:art2.

Tyrrell LE, Crow TR. 1994. Structural characteristics of old-growth hemlock-hardwood forests in relation to age. Ecology 75:370-386.

Vanderwel MC, Thorpe HC, Shuter JL, Caspersen JP, Thomas SC. 2008. Contrasting downed woody debris dynamics in managed and unmanaged northern hardwood stands. Canadian Journal of Forest Research 38:2850-2861.

Woods KD. 2000. Dynamics in late-successional hemlock-hardwood forests over three decades. Ecology 81:110-126.

Woods KD. 2004. Intermediate disturbance in a late-successional hemlock-northern hardwood forest. Journal of Ecology 92:464-476.

Woods KD. 2007. Predictability, contingency, and convergence in late succession: Slow systems and complex data-sets. Journal of Vegetation Science 18:543-554.

Zielonka T. 2006. Quantity and decay stages of coarse woody debris in old-growth subalpine spruce forests of the western Carpathians, Poland. Canadian Journal of Forest Research 36:2614-2622. 


\section{Figure 1}

Study area and examples of forest types.

A) The Huron Mts. study area with local topography (Lake Superior surface elevation is 180 $\mathrm{m}$ asl and the highest areas in the inset are about $550 \mathrm{~m}$ asl), and examples of plot groupings used in analyses: B) mixed conifer-hardwood stands; C) plots burned in 1830 with Tsuga dominance; D) Tsuga-dominated; and E) Acer-dominated hardwoods (all photos by Kerry Woods). 


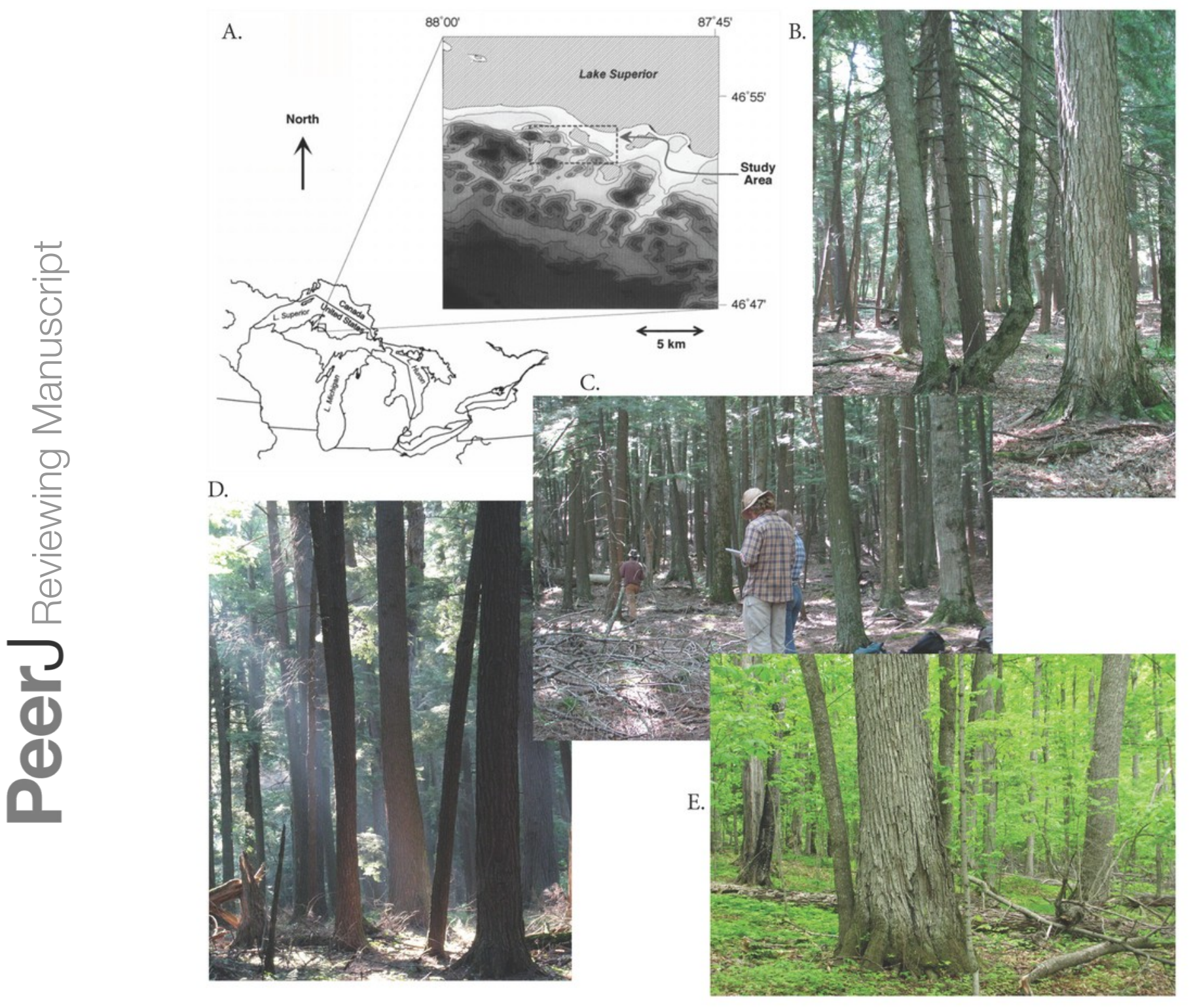




\section{Figure 2}

Examples of decay classes.

Examples of decay classes used in classifying CWD: A) recently fallen Acer saccharum, class 1; B) Acer saccharum log in class 2; C) Acer saccharum log in class 3 or 4; D) Tilia americana log in class 5 (all photos by Kerry Woods). 


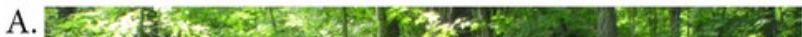
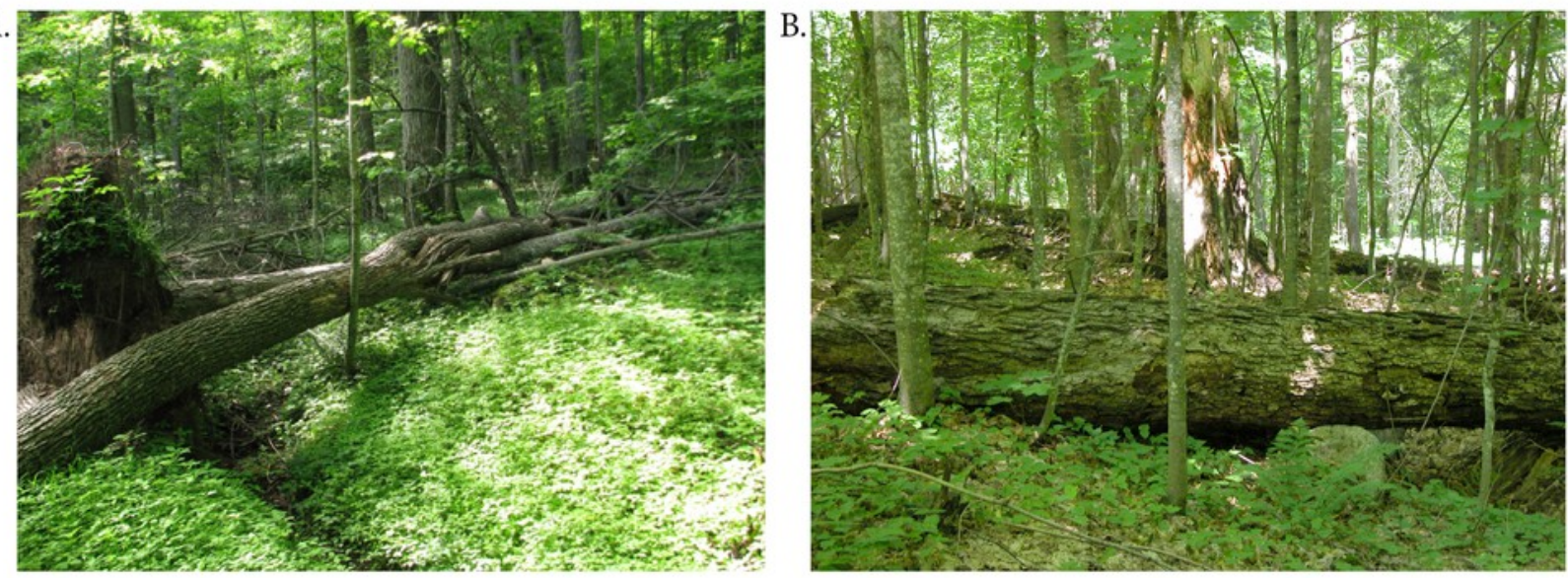

C.
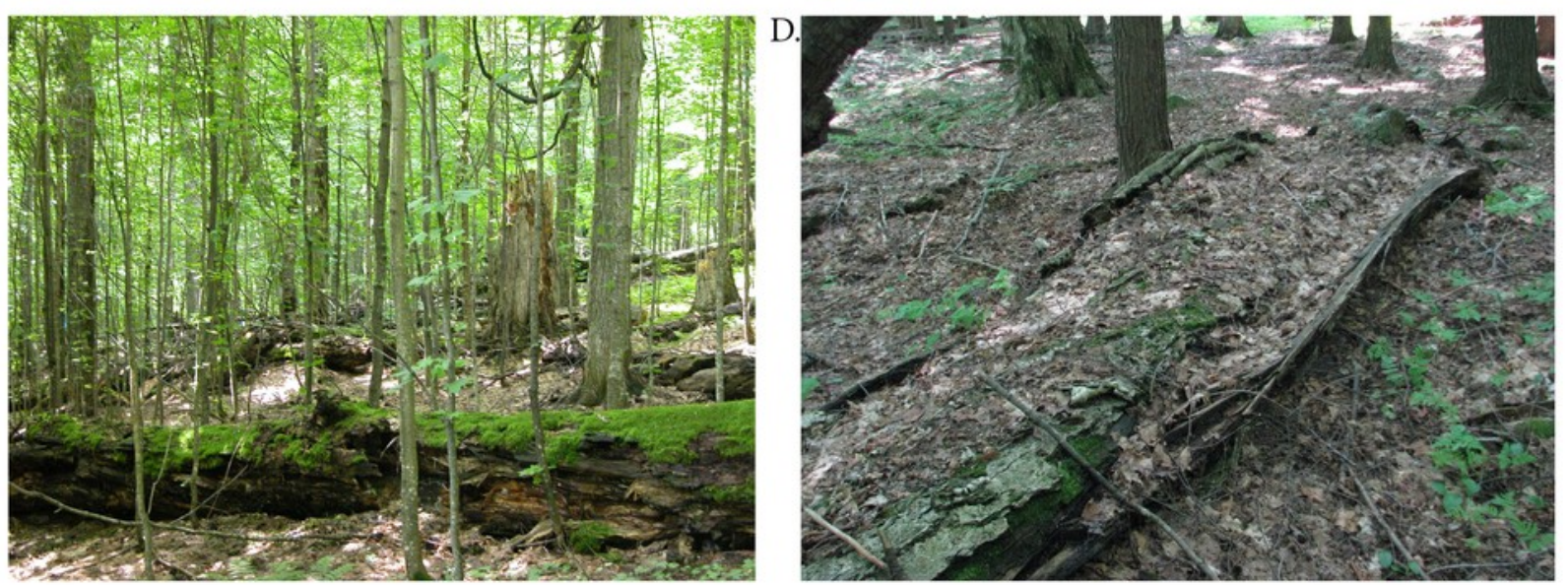


\section{Figure 3}

Trends in above-ground living biomass.

Trends in above-ground living biomass over time and among composition-based plot groups.

Overall average biomass density increased slightly, from $358 \mathrm{Mg} / \mathrm{ha}$ to $378 \mathrm{Mg} / \mathrm{ha}$ from 1962

to 2009. All plot groups show changes in direction of change over time. Highest values, for strongly Acer and Tsuga-dominated stands, are among the highest reported for eastern North America. 


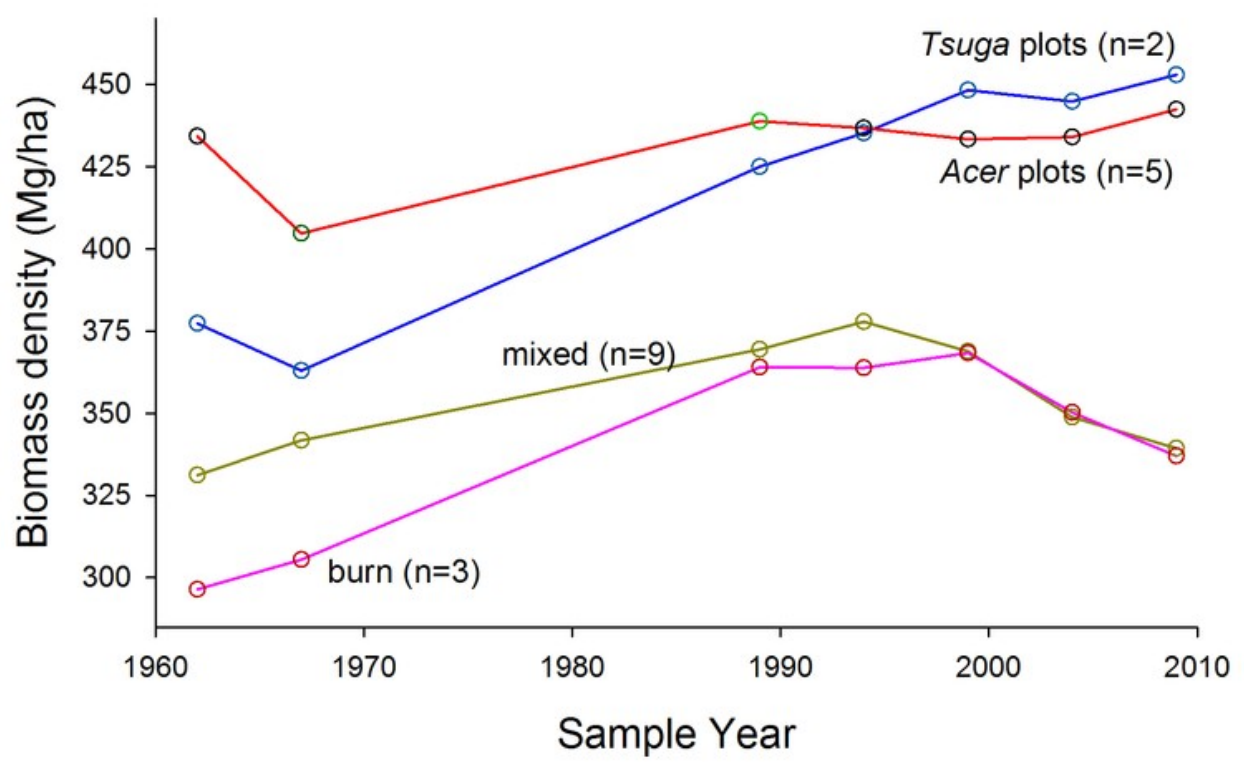

PeerJ reviewing PDF | (v2014:07:2414:1:1:NEW 26 Aug 2014) 


\section{Figure 4}

Cumulative distribution of biomass and CWD with respect to tree size.
A) Large trees increasingly dominate both living biomass and stem density over the study period, but B) CWD inputs through mortality do not show similar trends. A) Cumulative curves (from largest to smallest stems) for total biomass and stem density are higher for 2009 over nearly the full span of stem diameters. B) CWD input for the first 27 years of the study does not differ from curve for the last twenty years; numerically, mid-size canopy trees dominate inputs in the earlier period, but smaller stems dominate in the later period. 


\section{A. Living Biomass}

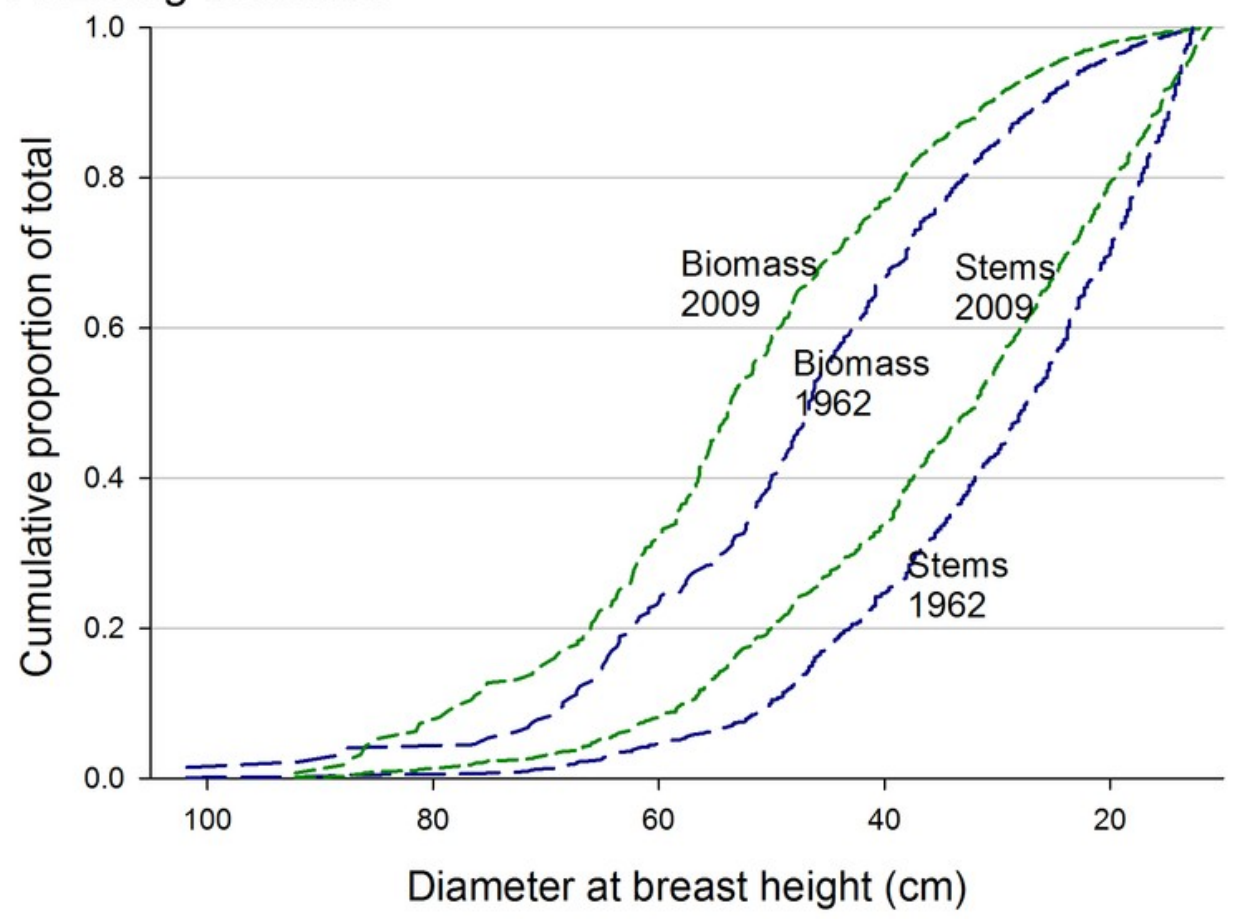

B. CWD Input

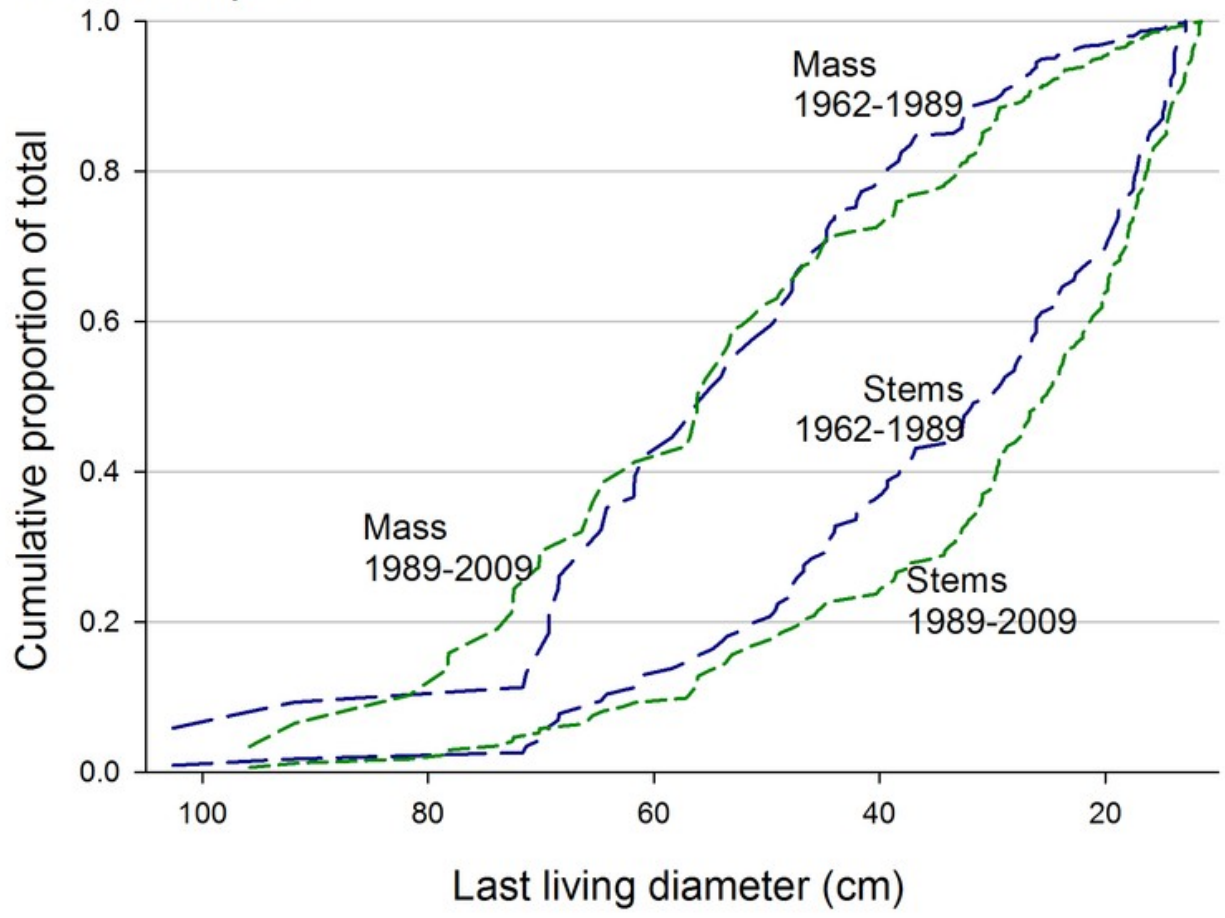




\section{Figure 5}

Proportion of living biomass in large trees.

Proportion of living biomass in large trees $(>70 \mathrm{~cm} \mathrm{dbh}$ ) increases over time for all plot groups except the 'burn' group. Mortality of early-successional species accounts for the loss of large trees in the burn group after 1999. 


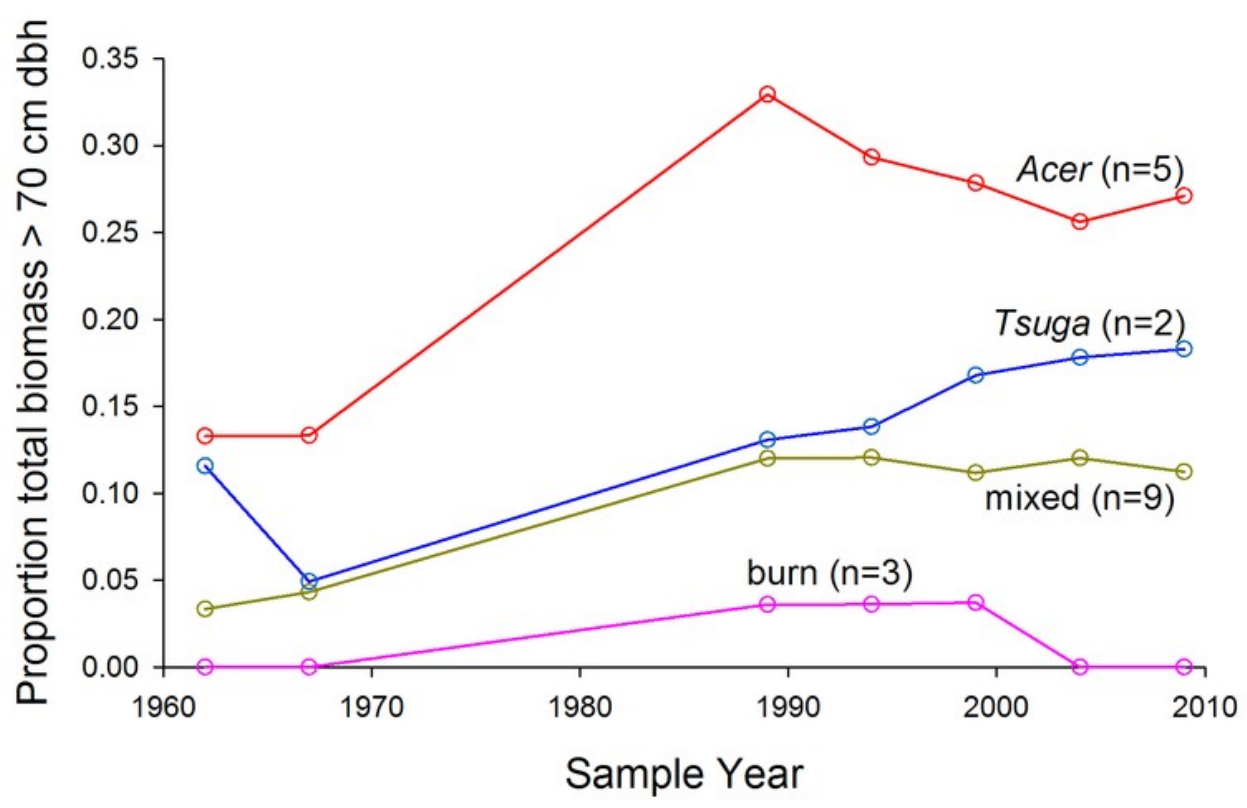

PeerJ reviewing PDF | (v2014:07:2414:1:1:NEW 26 Aug 2014) 


\section{Figure 6}

Living biomass by species over time.

In all plot groups, the most shade-tolerant canopy species (Tsuga canddensis and Acer saccharum) increasingly dominate biomass pools over the course of the study. Tsuga, where present, shows the largest proportional increase, while other species show generally decreasing biomass contributions. 

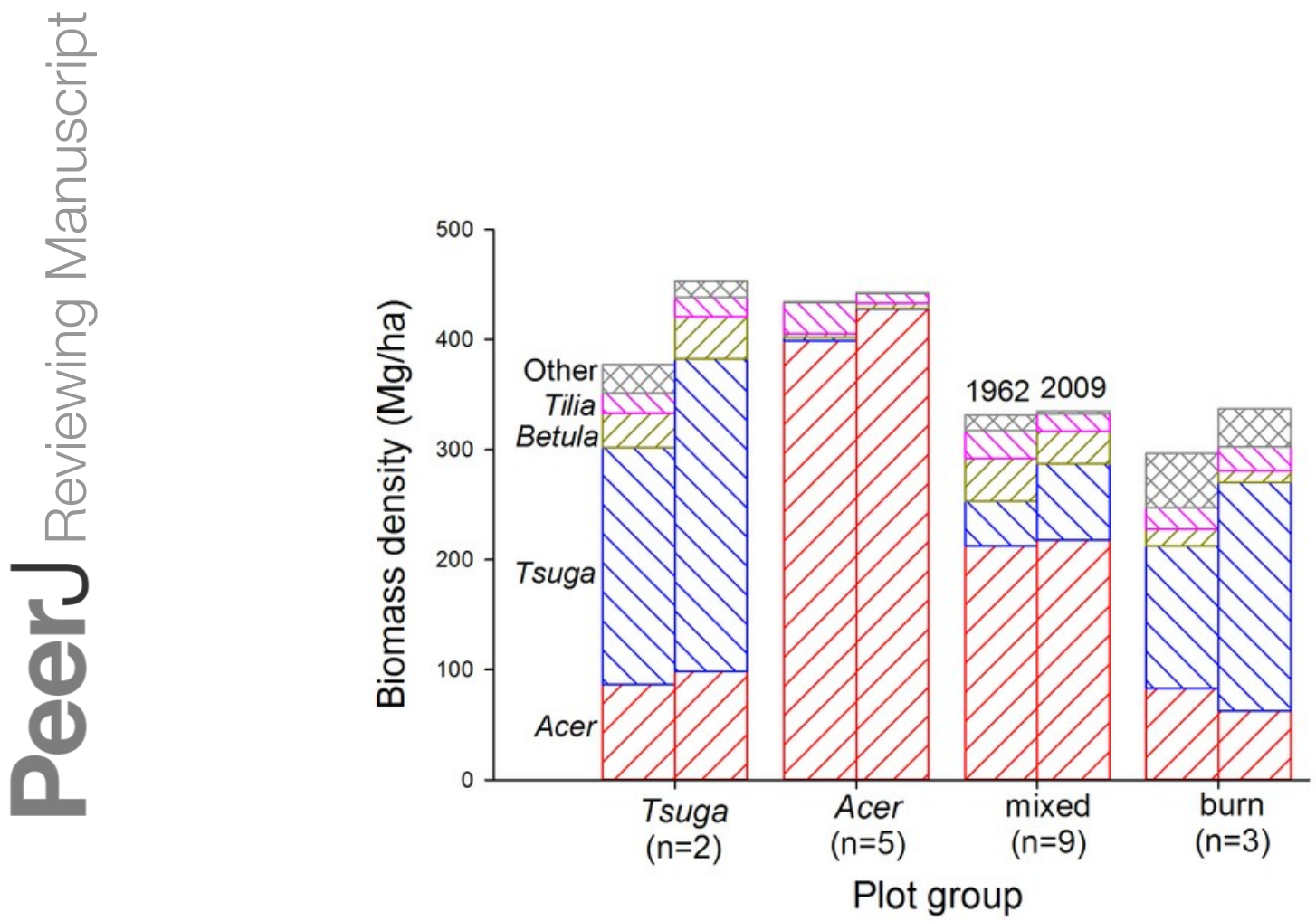

PeerJ reviewing PDF | (v2014:07:2414:1:1:NEW 26 Aug 2014) 


\section{Figure 7}

CWD distribution by decay class and plot group.

Coarse woody debris (CWD) pools in 2007 were highest in Acer-dominated plots in both total mass and voume. Acer plot group CWD pools -- composed entirely of hardwood species -are proportionally more dominated by more fully decayed material. 

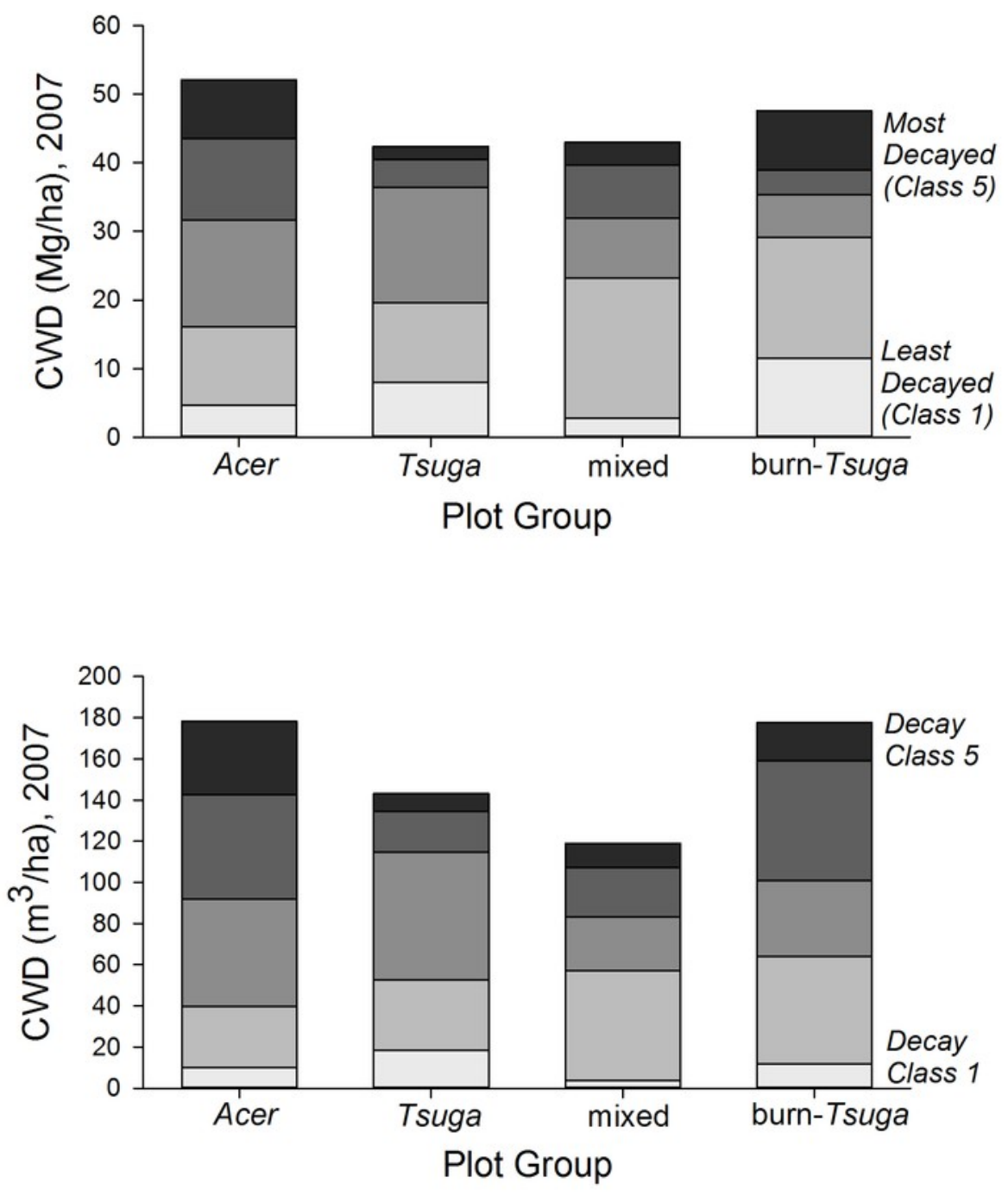


\section{Figure 8}

Estimated CWD inputs, 1962-2009.

Annualized coarse woody debris (CWD) inputs, estimated as bole mass of trees dying during each measurement period, are generally higher during the last two decades than for the first 27 years of the study. No systematic differences in trend are evident among plot groups.

Mass of trees dying during each measurement period is allocated uniformly across years within the measurement period. 


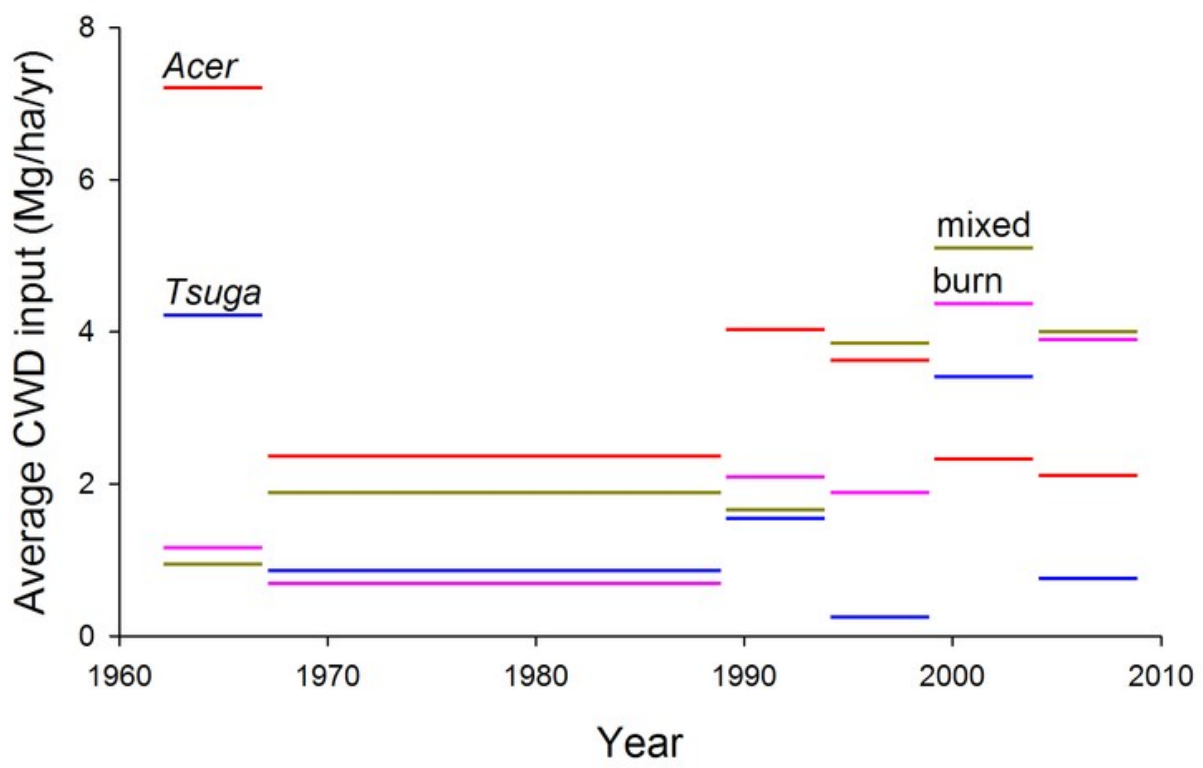

PeerJ reviewing PDF | (v2014:07:2414:1:1:NEW 26 Aug 2014) 


\section{Table 1 (on next page)}

Total aboveground biomass, stems $>12.5 \mathrm{~cm} \mathrm{dbh}(\mathrm{Mg} / \mathrm{ha})$ 


\begin{tabular}{l|rrrrrrr} 
& Year & & & & & \\
Plot Group & 1962 & 1967 & 1989 & 1994 & 1999 & 2004 & 2009 \\
\hline Acer $(\mathrm{n}=5)$ & 434.2 & 404.7 & 438.8 & 436.7 & 433.3 & 434.0 & 442.4 \\
Tsuga $(\mathrm{n}=2)$ & 377.3 & 363.0 & 425.0 & 435.2 & 448.2 & 444.8 & 452.9 \\
Mixed $(\mathrm{n}=9)$ & 331.2 & 341.8 & 369.5 & 377.9 & 368.9 & 348.9 & 339.4 \\
burn $(\mathrm{n}=3)$ & 296.5 & 305.5 & 364.0 & 363.9 & 368.3 & 350.3 & 337.0
\end{tabular}




\section{Table 2 (on next page)}

Coarse woody debris, average values by plot group, 2007 


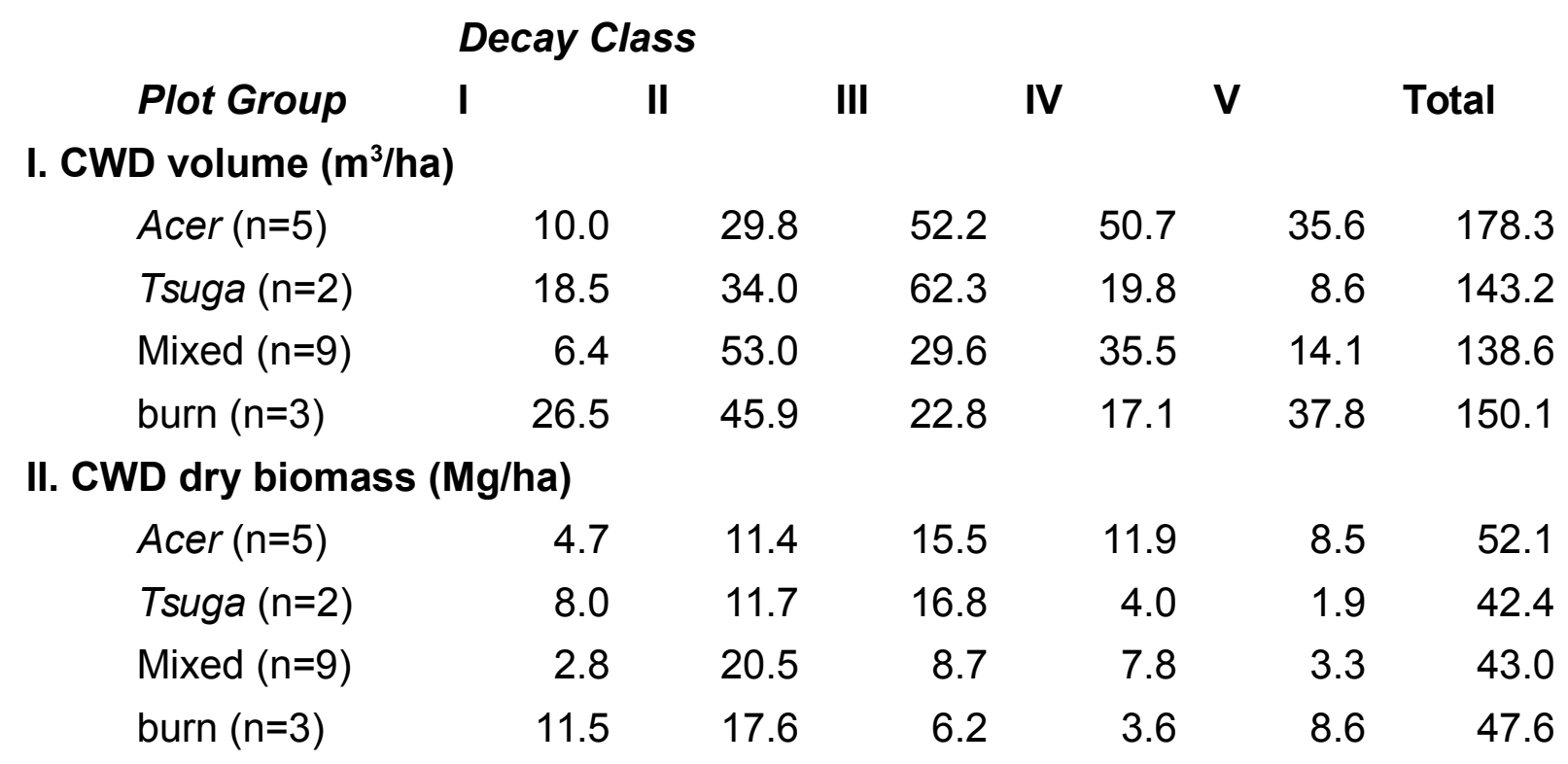




\section{Table 3 (on next page)}

Coarse woody debris input estimates by plot group and period 


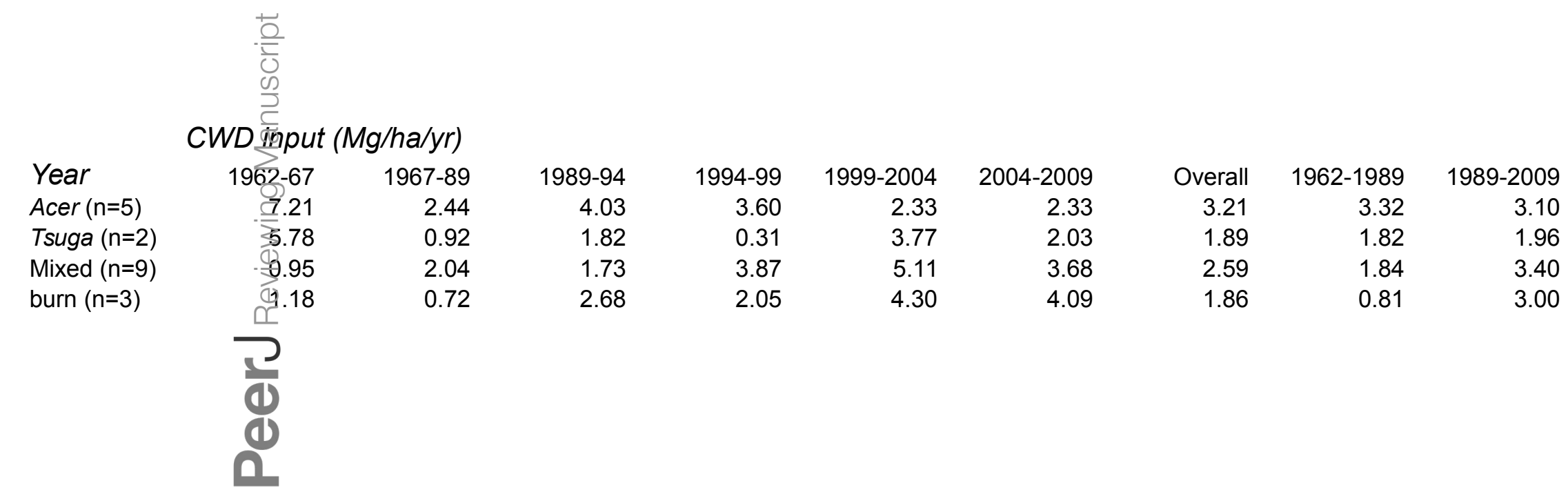

